\title{
Development of A Recombinant Murine Luteinizing Hormone Binding Protein As A Selective Hormone Inhibitor
}

\section{Yusuke Yamaguchi}

International University of Health and Welfare Graduate School of Medicine

\section{Yorino Sato}

International University of Health and Welfare Graduate School of Medicine

Kazuhiro Kawamura ( $\square$ kazuhironanami@gmail.com )

International University of Health and Welfare Graduate School of Medicine

\section{Research Article}

Keywords: hormone, luteinizing, ovulation, dysfunction, therapeutic

Posted Date: August 23rd, 2021

DOI: https://doi.org/10.21203/rs.3.rs-799109/v1

License: (c) (i) This work is licensed under a Creative Commons Attribution 4.0 International License.

Read Full License 


\title{
Development of a recombinant murine luteinizing hormone binding protein as a selective hormone inhibitor
}

\author{
Yusuke Yamaguchi ${ }^{1,2}$, Yorino Sato ${ }^{1}$, Kazuhiro Kawamura ${ }^{1,}$ * \\ ${ }^{1}$ Department of Obstetrics and Gynecology, Advanced Reproduction Research Center, \\ International University of Health and Welfare Graduate School of Medicine, Narita, Chiba, \\ 286-8686, Japan. \\ ${ }^{2}$ Innovative Drug Discovery Division, Drug Development Department, ASKA Pharmaceutical \\ Co., Ltd., Fujisawa, Kanagawa, 251-8555, Japan. \\ *Corresponding. kazuhironanami@gmail.com
}

\begin{abstract}
Physiological levels of luteinizing hormone (LH), in concert with follicle stimulating hormone (FSH), promote ovarian follicular development and ovulation. However, high LH levels associated with ovarian dysfunction have been shown to inhibit these processes. Thus, developing a selective LH inhibitor could be potentially useful for treating ovarian dysfunction. Here, we developed a mouse LH-binding protein (mLBP) composed of the extracellular domain of LH receptors as a selective inhibitor of mouse LH. After transient introduction of mLBP expressing vectors into Expi293F cells, mLBP was obtained as a soluble protein via a cleavage reaction with thrombin. The binding ability of mLBP for mouse LH was confirmed using sera containing high LH and FSH collected from ovariectomized (OVX) mice. The bioactivity of mLBP was demonstrated by inhibition of cAMP and testosterone productions induced by OVXmouse serum in mouse Leydig MLTC-1 cells expressing LH receptors. In contrast, mLBP did not bind mouse FSH and inhibit cAMP production induced by OVX-mouse serum in 293 cells expressing mouse FSH receptors. The mLBP also showed binding affinity to human LH (hLH), and inhibited hLH-induced cAMP production in MLTC-1 cells. Thus, the mLBP selectively suppresses the action of $\mathrm{LH}$ and is a potential therapeutic agent for ovarian dysfunction.
\end{abstract}

\section{Introduction}

In recent years, the age of women at the time of marriage and childbirth has increased in developed countries. As the number of residual follicles in the ovaries and egg quality decline with age, the risk of infertility increases in aging women ${ }^{1}$. In ovarian dysfunction, including aging infertility, follicle development is impaired resulting in ovulation disorder, and these patients are resistant to the ovarian stimulation drugs, such as gonadotropins [follicle stimulating hormone (FSH) and luteinizing hormone (LH)] and anti-estrogen preparations, to 
promote follicle development ${ }^{2}$. Increasing doses and/or dosing frequencies of gonadotropin preparations are routinely used in ovarian dysfunction patients, the efficacy of this approach is limited together with high treatment costs ${ }^{3}$. Because the child-bearing age of women tends to become further older, establishing a novel method of ovarian stimulation for patients with ovarian dysfunction is anticipated.

Balasch et al. proposed the LH window hypothesis in which abnormally elevated serum LH levels could lead to deteriorate effects, including growth arrest of granulosa cells, induction of follicular atresia, premature follicular luteinization, and impaired ovarian development ${ }^{4}$. In cases of ovarian dysfunction, the amount of estradiol production from the granulosa cell in ovarian follicles decreases due to fewer growing follicles in these patients, decreasing the negative feedback of estradiol at the pituitary gland and hypothalamus for gonadotropin production, ${ }^{5}$. A recent study reported that patients with severe ovarian dysfunction, namely premature ovarian insufficiency (POI) who developed hypergonadotropinemia did not display follicular growth when treated with human menopausal gonadotropin (HMG) alone. However, the simultaneous administration of the HMG with a GnRH agonist to decrease gonadotropin levels resulted in follicular growth. Moreover, eggs could be retrieved under in vitro fertilization-embryo transfer (IVF-ET) program ${ }^{6}$. Thus, the high LH environment is likely involved in the disorder of follicle development in women with ovarian dysfunction. However, besides $\mathrm{LH}$, the level of FSH is also high in ovarian dysfunction. Therefore, the association between this high LH environment and impaired folliculogenesis in ovarian dysfunction conditions has been difficult to verify via in vivo analysis, unless applying a selective $\mathrm{LH}$ inhibitor.

Since no selective LH inhibitor for animal study and future human clinical trial is available, we sought to develop a mouse LH-binding protein (mLBP), an extracellular domain protein of the $\mathrm{LH}$ receptor ${ }^{7}$ designed to enable the selective inhibition of $\mathrm{LH}$ action in mice with ovarian dysfunction, to ultimately permit an in vivo analysis of the association between high $\mathrm{LH}$ environment and folliculogenesis disorders. The anti-LH activity of mLBP was evaluated in vitro using mouse Leydig-derived MLTC-1 cells that express LH receptors endogenously. Moreover, selectivity of mLBP for mouse LH was also confirmed using mouse FSH receptor stably expressing 293 cells. The anti-LH activity of mLBP to human LH, which is highly homologous to human $\mathrm{LH}$, and the binding ability of mLBP were also assessed.

\section{Results}

\section{Genetic construction and production of mLBP}

To generate mLBP, an extracellular domain protein of the mouse LH-receptor, we modified the human LtCD8 gene, a fusion gene produced by Osuga et $\mathrm{al}^{7}$. The human LtCD8 gene is 
designed to express the extracellular domain of the binding human LH receptor in the CD8 transmembrane domain through the thrombin cleavage site ${ }^{7}$. We changed the extracellular domain of the human $\mathrm{LH}$ receptor to the DN Asequence of the extracellular domain of the mouse LH receptor to construct the pcDNA3.1 (+)-mouse LtCD8 gene (Fig. 1A).

The pcDNA3.1 (+)-human LtCD8 gene and pcDNA3.1 (+)-mouse LtCD8 gene were introduced into Expi293F cells. And these cells were treated with thrombin after two or three days to free the soluble human and extracellular domains of mouse LH receptor in the culture supernatants. The soluble mLBP could be detected by immunoblot with the anti-FLAG antibody (Fig. 1B). No mLBP was observed in the culture supernatant of cells without thrombin (Fig. 1B). Human LtCD8 and mouse LtCD8 full-length proteins were detected in the lysate of each cell after thrombin treatment (Fig. 1B; Supplementary Fig. 1).

\section{Interaction between mLBP and mouse gonadotropins}

Natural LH purified from mice is not commercially available. Therefore, the binding affinity of mLBP for mouse LH was confirmed using sera containing high LH and FSH collected from ovariectomized (OVX) mice. After incubation with a mixture of $12.5 \%$ OVX-mouse sera and mLBP-enriched culture supernatant ( $300 \mu \mathrm{g} / \mathrm{mL}$ Flag-tagged $\mathrm{mLBP}$ ), which were added to the FLAG M2 antibody-affinity gel, the gonadotropin levels in the filtrate were measured. The free LH levels in the control and mLBP groups were $0.659 \pm 0.011 \mathrm{ng} / \mathrm{mL}$ and $0.265 \pm 0.011 \mathrm{ng} / \mathrm{mL}$ respectively.Thus, significant reduction of LH immunoactivity was found in the mLBP group. On the other hand, free FSH levels in the control and mLBP groups were $1.382 \pm 0.044 \mathrm{ng} / \mathrm{mL}$ and $1.572 \pm 0.023 \mathrm{ng} / \mathrm{mL}$ each. There was no reduction of FSH was found in the $\mathrm{mLBP}$ group (Fig. 2A). Then, mLBP bound to anti-FLAG M2 agarose affinity gel was eluted by competition using 3 x FLAG peptide. mLBP in the eluate was detected by immunoblot using an anti-FLAG antibody (approximately $60 \mathrm{kDa}$ ) (Fig. 2B; Supplementary Fig. 2). Although the concentration of LH in the eluate was measured, it was not detected.

\section{Cell bioassay to evaluate the anti-LH activity of mLBP}

To evaluate the anti-mouse LH activity of mLBP, we used sera from OVX mice (OVX-mouse sera). Also, we used mouse MLTC- 1 cells ${ }^{8}$, which express LH receptors but not FSH receptors, to detect the inhibitory effect of mLBP against LH activity.

The LH and FSH levels in the sera collected from sham-operated mice (sham-mouse sera) were $0.32 \pm 0.05 \mathrm{ng} / \mathrm{mL}$ and $0.89 \pm 0.25 \mathrm{ng} / \mathrm{mL}$, whereas they increased to $4.76 \pm 0.76 \mathrm{ng} / \mathrm{mL}$ and $26.21 \pm 1.97 \mathrm{ng} / \mathrm{mL}$ respectively in OVX-mouse sera.

When MLTC-1 cells were cultured with culture medium containing 2.5 and 5\% OVX-mouse sera (LH concentration in the culture medium: 0.12 and $0.24 \mathrm{ng} / \mathrm{mL}$ ) and with culture medium containing 5\% sham-mouse sera (LH concentration in the culture medium: $0.02 \mathrm{ng} / \mathrm{mL}$ ) for $1 \mathrm{~h}$, cAMP production increased in a LH concentration-dependent manner (Fig. 3A). The mLBP- 
enriched culture supernatant inhibited cAMP production induced by 5\% OVX-mouse sera in a concentration-dependent manner at 10 to $100 \mu \mathrm{g} / \mathrm{mL}$ FLAG-tagged mLBP (Fig. 3B). To eliminate the influence for cAMP production by non-specific factors in MLTC-1 cells, we also measured of testosterone production, the primary physiological effect of $\mathrm{LH}$ on testicular Leydig cells. The testosterone concentration in the supernatants of MLTC-1 cells treated with medium containing $5 \%$ sham-mouse sera for $1 \mathrm{~h}$ was $12.6 \pm 4.7 \mathrm{nmol} / \mathrm{L}$, and was increased to $855.0 \pm 234.4 \mathrm{nmol} / \mathrm{L}$ when the cells were treated with medium containing $5 \%$ OVX-mouse sera ( $\mathrm{n}=4$ each). The testosterone production induced by $5 \%$ OVX-mouse sera was almost completely inhibited by $100 \mathrm{nmol} / \mathrm{L}$ abiraterone, a small molecule inhibitor of cytochrome P17 (CYP17), which serves as the key enzyme of testosterone production (Fig. 3C). The mLBPenriched culture supernatants inhibited testosterone production induced by OVX mouse-sera in a concentration-dependent manner at 10 to $300 \mu \mathrm{g} / \mathrm{mL}$ FLAG-tagged mLBP (Fig. 3C). To investigate cytotoxicity of mLBP, we confirmed the viability of MLTC-1 cells at end of the culture. The cells were treated with mLBP-enriched culture supernatant at a minimum and maximum effective concentration ( 10 and $300 \mu \mathrm{g} / \mathrm{mL}$ Flag-tagged $\mathrm{mLBP}$ ), there was no difference compared with the control group (Fig. 3D). Furthermore, the cells were subconfluent in all group, and did not show abnormal morphology.

\section{Effect of mLBP on mouse FSH activity}

We investigated specificity of mLBP actions using 293 cells stably expressing mouse FSH, but not LH, receptors. The 293 cells were cultured with medium containing 2.5 and 5\% OVXmouse sera (FSH concentration in the culture medium: 1.31 and $2.62 \mathrm{ng} / \mathrm{mL}$ ) and $5 \%$ shammouse sera (FSH concentration in the culture medium: $0.04 \mathrm{ng} / \mathrm{mL}$ ) for $1 \mathrm{~h}$, cAMP production increased in a concentration-dependent manner (Fig. 4A). And cAMP production in 293 cells cultured for $1 \mathrm{~h}$ with culture medium containing $5 \%$ OVX-mouse sera was not inhibited by mLBP-enriched culture supernatants at 10 to $100 \mu \mathrm{g} / \mathrm{mL}$ FLAG-tagged mLBP, showing no inhibitory effect of mLBP for mouse FSH activity (Fig. 4B).

\section{Anti-LH activity of mLBP on recombinant human LH}

Next, we confirmed the binding affinity of mLBP for rhLH. After incubation with a mixture of $1 \mathrm{ng} / \mathrm{mL}$ rhLH and mLBP-enriched culture supernatant (100 $\mu \mathrm{g} / \mathrm{mL}$ Flag-tagged mLBP), they were added to the FLAG M2 antibody-affinity gel, the hLH levels in the filtrate were measured. The concentrations of rhLH in the control and $\mathrm{mLBP}$ groups were $0.905 \pm 0.005 \mathrm{ng} / \mathrm{mL}$ and $0.195 \pm 0.003 \mathrm{ng} / \mathrm{mL}$, respectively, which were significantly reduced in the mLBP group (Fig. $5 A)$. Then, mLBP bound to anti-FLAG M2 agarose affinity gel was eluted by competition using $3 \times$ FLAG peptide. mLBP in the eluate was detected by immunoblot using an anti-FLAG antibody (approximately $60 \mathrm{kDa}$ ) (Fig. 5B; Supplementary Fig. 3). Although the concentration of rhLH in the eluate was measured, it was not detected. 
Next, we investigated whether mLBP could suppress the LH-activity of rhLH in MLTC-1 cells. These cells were cultured for $1 \mathrm{~h}$ with medium containing $1 \mathrm{ng} / \mathrm{L} \mathrm{rhLH}$, showing a significant increase in cAMP production (Fig. 5C). The mLBP-enriched culture supernatants concentrationdependently inhibited cAMP production induced by $1 \mathrm{ng} / \mathrm{mL}$ rhLH treatment for $1 \mathrm{~h}$ at 10-100 $\mu \mathrm{g} / \mathrm{mL}$ Flag-tagged mLBP (Fig. 5D).

\section{Discussion}

In this study, we generated mLBP, the ligand-binding region of mouse LH receptors, by incorporating extracellular domain of mouse LH receptor genes into the expression system for membrane-immobilized fusion proteins developed by Osuga et al. ${ }^{7}$ mLBP could act as a novel agent that exhibited the binding affinity to mouse LH and inhibited the LH receptor signals activated by $\mathrm{LH}$ as a functional antagonist. Because mLBP had no affinity to mouse FSH and was a soluble agent that selectively inhibited LH activity without cellular toxicity, it serves as a powerful study tool to analyze the roles of high LH in follicular development and ovulation in in vivo systems in mice with ovarian dysfunction.

Currently, two different types of agents to modulate gonadotropin (FSH and LH) secretion. One is estrogen/progesterone drugs that promote negative feedback to the hypothalamus and pituitary gland and the other type of agent is GnRH agonists and antagonists acting on GnRH receptors in the pituitary gland. Although these drugs are effective to regulate gonadotropin secretions, they simultaneously change both FSH and LH productions. Therefore, there is no current drug that targets LH actions only in the clinical market. In preclinical studies, selective FSH inhibitors including small-molecule compounds, peptides, and antibodies against the FSH-receptor are under development. A peptide to inhibit the binding of FSH to its receptor and an anti-FSH beta monoclonal antibody have been reported to suppress FSH actions in vivo in mice ${ }^{9,10}$. As a selective LH inhibitor, BAY-298, a small-molecule allosteric modulator for the LH receptor, has been reported, but this inhibitor does not act on mouse LH receptors ${ }^{11}$. Therefore, the mLBP developed herein is the first selective mouse LH-specific inhibitor.

Previously, Osuga et al. developed the soluble LH-binding protein, human LBP (hLBP), using the human LH receptor extracellular domain ${ }^{7}$. However, the human LH receptor has shown not to react with rat, equine, or ovine $\mathrm{LH}^{12}$. Indeed, we generated the 293 cells expressing human LH receptor stably and treated these cells with OVX-mouse serum, but such treatment did not induce cAMP production (data not shown). Therefore, hLBP could not be used for in vivo studies in mice due to its low binding affinity to rodent LH. Interestingly, mLBP displayed binding affinity not only to mouse $\mathrm{LH}$, but also to rhLH. 
Although the earlier study by Osuga et al. did not prepare large quantities of hLBP, they used the baculovirus-insect cell system to obtain a large amount of soluble human FSH-receptor extracellular domain expressing as membrane-immobilized fusion proteins ${ }^{7}$. In this system, post-translational modifications similar to mammalian systems could add to the recombinant protein, but it takes long time to prepare the recombinant baculovirus. Further, there is a risk of residual baculovirus contamination in the purified recombinant protein. In the present study, we used the Expi293F cells derived from human fetal kidneys as host cells for mouse LtCD8 expression. The Expi293F cell line shows high transfection efficiency and is adapted for floating growth of the cells in serum-free medium ${ }^{13}$. Thus, mLBP can be prepared in large quantities in a short time by the transient transfection. This system also has an advantage to allow the direct administration of recombinant proteins to animals without the risk of virus contamination.

For evaluation of LH and FSH activities, testosterone production in primary cultures of mouse and rat testicular Leydig cells ${ }^{14}$ and aromatase-activity in primary cultures of granulosa and Sertoli cells ${ }^{12}$ have been used as well established bioassays respectively. However, these methods need to obtain cells by sacrificing animals. Therefore, we developed simple and rapid bioassays to assess the activity of LH and FSH using cell-lines of mouse testicular Leydigderived MLTC-1 cells and mouse FSH stably expressing 293 cells. MLTC-1 cells express LH receptors endogenously and respond to LH stimuli to induce cAMP production. LH treatment also induces the expressions of CYP17 and steroid-metabolizing enzymes in MLTC-1 cells, resulting in increase in progesterone and testosterone productions ${ }^{8,15}$. As native LH purified from mice is not available commercially, we used the OVX-mouse sera containing high levels of FSH and LH to confirm cAMP and testosterone productions in MLTC-1 cells. Because there is no commercially available cell line that specifically responds to mouse FSH to confirm the specificity of mLBP, we generated a cell line expressing transgenic for mouse FSH receptor stably that do not express endogenous gonadotropin receptors. Unlike primary granulosa cells, this cell line do not produce estradiol in response to FSH stimulation, but could produce cAMP by OVX-mouse serum treatment. By combining these cells, we established assays that could selectively assess the bioactivity of LH among gonadotropins in mouse serum and proved the selective anti-LH activity of mLBP indexed to cAMP and testosterone productions. $\mathrm{mLBP}$ inhibited testosterone production to levels similar to the CYP19A1 inhibitor, abiraterone, a drug for castration-resistant prostate cancer, indicating the high potential of $\mathrm{mLBP}$ as a LH inhibitory agent. Furthermore, we confirmed that no cytotoxicity in $\mathrm{mLBP}$ and thus mLBP was considered to have a lower risk of toxic effects when used in in vivo studies.

To confirm the anti-LH activity of mLBP in in vitro studies, mLBP, produced in the cell culture supernatant after thrombin response, was prepared at a small scale by concentrating the 
culture supernatant without purification as same as the previous publication by Osuga et al. ${ }^{7}$. Thus, besides thrombin and mLBP, the mLBP solutions may contain some other proteins in the culture supernatant. To exclude the potential effects of thrombin and proteins other than mLBP in the mLBP solutions in each experiment, we used the control solution concentrated from cell culture supernatant of Expi293F cells transfected with pcDNA 3.1(+) vector alone after thrombin treatment by applying the same method used in the preparation of mLBP. Although we attempted to prepare a purified mLBP using the FLAG tag added to mLBP by FLAG M2 affinity gel and FLAG peptide to further prove the specific action of $\mathrm{mLBP}$, purified $\mathrm{mLBP}$ showed no anti-LH activity. This result may be caused by changes in the binding of LHreceptors with ligands during the mLBP purification process due to their protein conformation and the need for weak intermolecular interactions, such as the ionic binding of both ${ }^{16,17}$. We will clarify this issue in future study.

In this study, the ability of mLBP to bind to mouse LH was demonstrated by the decreased free LH levels in the filtrate of the FLAG affinity gel column after adding a mixture of mLBP solutions and OVX-mouse serum to FLAG affinity gel. The binding of mLBP on the FLAG affinity gel was confirmed by immunoblot using an anti-FLAG antibody against the eluate obtained by washing the FLAG affinity gel with FLAG peptide. Because mLBP was bound to FLAG on the affinity gel, the LH in the mixed solution of mLBP and OVX-mouse serum was bound to mLBP-FLAG, resulting in decline of the LH concentration in the filtrate of the column. Although we also attempted to determine LH levels in the eluate by the FLAG peptide, those levels were found to be below the measured sensitivities. This might be explained that the anti-LH antibody could not detect LH due to changes in the antigen recognition site by forming a complex of mouse LH with mLBP. Using a similar method, we demonstrated that mLBP bound to ligands of human LH receptor, human recombinant LH.

In patients with decreased ovarian reserve including aging and POI patients, the high gonadotropin environment induced by low ovarian function seems to be involved in disorders of follicular growth and ovulation. In addition to the LH window concept, an earlier study demonstrated that a high LH state impaired FSH-dependent rat antral follicle growth by suppressing FSH receptor expressions in granulosa cells and reduced GDF-9 production, an oocyte-derived factor known to have important roles for follicular development ${ }^{18}$. However, experiments to selectively ameliorate high LH level in ovarian dysfunction mice are needed for elucidating the effects of high LH state in impaired follicular growth and ovulation. Here, we developed a novel selective mouse LH inhibitor, mLBP, allowing us to conduct these in vivo animal studies. As demonstrated in this study, the effects of a high-LH environment on disorders of follicular growth and ovulation could be assessed by administering mLBP-enriched culture 
supernatant to ovarian dysfunction mice. Different mLBP purification methods will be attempted in the future to establish a method for purifying functional mLBP.

\section{Methods}

Construction of the expression vector for chimeric mouse LtCD8 receptor, cell cultures, immunoblot, animal experiments, hormonal assays, and mLBP-ligand binding assay are provided in SI Methods.

\section{Gene transfection and protein expression}

The pcDNA3.1 $(+)$ - mouse LtCD8 expression vector was transfected into Expi293F cells using ExpiFectamine 293 Transfection kit (Catalog no. A14635, Thermo Fisher Scientific, Waltham, MA, USA) according to the manufacturer's instructions. Briefly, the Expifectamin 293 Reagent and Opti Plex Complex Buffer (Catalog no. A4096801, Thermo Fisher Scientific) included in the kit were mixed and incubated at room temperature for $5 \mathrm{~min}$. Thereafter, the expression vector for chimeric mouse LtCD8 receptor solutions was added and the mixture was allowed to further react at room temperature for 10-20 min. The Expifectamin 293 Reagent mixture was added to cells cultured in shake flasks under standard procedures at $125 \mathrm{rpm}$ and $37{ }^{\circ} \mathrm{C}$ with $8 \% \mathrm{CO}_{2} \mathrm{a}$. At 16 to $18 \mathrm{~h}$ from the start of culture, the enhancer reagents in the ExpiFectamine $^{\mathrm{M}} 293$ Transfection kit were added and the mixture was cultured for one or two days.

Expi293F cells forced to express the recombinant proteins were harvested and the cells were washed once using phosphate buffered saline (-). Subsequently, cells were suspended in a RPMI1640 medium (Catalog no. 06261-65, Nacalai Tesque) containing 5 U/mL thrombin (Catalog no. 27-846-01, Cytiva, Marlborough, MA, USA) and allowed to react in an incubator set at $37^{\circ} \mathrm{C}$ for $1 \mathrm{~h}$. Argatroban monohydrate $(10 \mu \mathrm{mol} / \mathrm{L}$; Catalog no. A2705, Tokyo Kasei Industry Co, Tokyo, Japan) was added to stop the cleavage response by thrombin. Centrifuged at $2,450 \mathrm{x}$ g and $4{ }^{\circ} \mathrm{C}$, and the culture supernatants were collected. Subsequently, the supernatant was ultrafiltered using a VIVA SPIN 20-10K (Catalog no. VS2001, Sartorius, Gottingen, Germany) at a centrifugation speed of $2,450 \mathrm{x}$ and $4{ }^{\circ} \mathrm{C}$. Subsequently, the supernatant was further concentrated using a Amicon Ultra 0.5-10 K (Catalog no. UFC801024, Merck Millipore, MA, USA) at a centrifugation speed of $2450 \mathrm{x}$ and $4{ }^{\circ} \mathrm{C}$. An mLBP culture supernatant enriched more than 100-fold was prepared, and the concentration was measured using a FLAG ELISA kit (Catalog no. 501560, Cayman Chemicals, MI, USA). The calculated concentration was used as the Flag-tagged mLBP concentration of the mLBP enriched culture supernatant. The concentration for the mLBP treatment group in each experiment was expressed as the Flagtagged mLPP concentration. Total protein levels were also determined using a BCA Protein 
Assay Kit (Catalog no. 23225, Thermo Fisher Scientific), and mLBP-enriched culture supernatants were stored at $-80{ }^{\circ} \mathrm{C}$ until use.

mLBP-enriched culture supernatants contain thrombins and nonspecific proteins. Therefore, the control of the mLBP-enriched culture supernatant was used as a vehicle-enriched culture supernatant where a pcDNA3.1 (+) plasmid vector was genetically introduced into Expi293F cells in the same manner as that performed for the production of enriched mLBP culture supernatant. Further, the culture supernatant obtained by treating the cells with thrombin was used as the concentrated vehicle-enriched culture supernatant. In each experiment, vehicleenriched culture supernatant was added to the treatment solution of the control group to ensure that the total protein concentration in the treatment solution of the control group and that of the mLBP group was the same.

\section{cAMP measurements}

Intracellular cAMP levels were measured using a homogeneous time-resolved fluorescence (HTRF ${ }^{\circ}$ ) assay kit (Catalog no. 62AM4PEC, Perkin Elmer), according to the manufacturer's instructions. MLTC-1 cells or 293-mFSHR cells were seeded at density of 1 x $10^{4}$ cells $/ 5$ $\mu \mathrm{L} /$ well in each well of a white round bottom 384 well plate (Catalog no. 784904, Greiner BioOne, Frickenhausen, Germany). For the experiment where the anti-mouse LH activity of mLBP was evaluated in MLTC-1 cells and where the anti-mouse FSH activity of mLBP was evaluated in mouse FSHR stably expressing 293 cells, the control group was supplemented with 5\% OVX-mouse sera and vehicle-enriched culture supernatant while the mLBP group was supplemented with a mixture of 5\% OVX-mouse sera and mLBP-enriched culture supernatant $(3,10,30$, or $100 \mu \mathrm{g}$ per mL Flag-tagged $\mathrm{mLBP})$ at $5 \mu \mathrm{L}$ per well, respectively. In the experiment where the anti-hLH activity of mLBP was evaluated in MLTC-1 cells, $1 \mathrm{ng} / \mathrm{mL}$ recombinant hLH (rhLH, catalog no. 8899-LH-010, R\&D systems, Minneapolis, MN, USA) and vehicle-enriched culture supernatant were added to the control group. The negative control group was also supplemented with the $1 \mathrm{x}$ stimulation buffer supplied as part of the kit. After a 1-h reaction in an incubator set at $37^{\circ} \mathrm{C}, \mathrm{d} 2$, an acceptor phosphor, was added to the wells, except for that of the negative control at $5 \mu \mathrm{L} /$ well, and Eu-cryptate, a donor phosphor, was added to all wells at $5 \mu \mathrm{L} /$ well. The reaction was allowed to proceed at room temperature for 1 h. Envision Multilabel Reader (PerkinElmer) and GraphPad Prism 9 (GraphPad Software) were used as the measuring device and analysis software, and cAMP levels were calculated for each group. The cAMP concentration of each sample was calculated by subtracting the mean cAMP concentration of the negative control group as a background. Subsequently, the relative $\%$ of the mean cAMP level in the mLBP group relative to the mean cAMP level (control $=100 \%)$ in the control group was calculated, and the results are presented as mean $\pm \mathrm{SD}$ ( $\mathrm{n}=4$ each). 
Testosterone levels in culture media

MLTC-1 cells were cultured in 10\% steroid-free serum-containing RPMI1640 medium for 3 days, then plated in 96-well plates at $5 \times 10^{4}$ cells/well and pre-cultured for $24 \mathrm{~h}$. Thereafter, RPMI1640 was added to the negative control group; 5\% OVX-mouse sera and vehicle-enriched culture supernatant were added to the control group; 5\% OVX-mouse sera and $100 \mathrm{nmol} / \mathrm{L}$ abiraterone (a CYP17A1 inhibitor; Catalog no. A2868, Tokyo Kasei Industry Co, Tokyo, Japan) were added to the abiraterone treatment group; and 5\% OVX-mouse sera and mLBP-enriched culture supernatant $(10,30,100$, or $300 \mathrm{~g} / \mathrm{mL}$ Flag-tagged $\mathrm{mLBP})$ were added to the $\mathrm{mLBP}$ treatment group. The medium was replaced with RPMI 164 medium, which contained $2 \mu \mathrm{mol} / \mathrm{L}$ pregnenolone (Catalog no. P0477, Tokyo Kasei Industry Co.), a testosterone synthesis substrate.

After one day culture, testosterone levels in the culture supernatants were measured using a Testosterone HTRF kit (Catalog no. 64 TESPEG, Perkin Elmer), according to the manufacturer's instructions. Briefly, the sample was added to each well of a white round bottom 384 well plate at $10 \mu \mathrm{L} /$ well. Thereafter, Testosterone-XL655 was added to wells except that of the negative control at $5 \mu \mathrm{L}$ per well. The anti-Testosterone-Eu ${ }^{3+}$ Cryptate antibody was added to all wells at $5 \mu \mathrm{L}$ per well. After the reaction was allowed to proceed at room temperature for 1 h, Envision Multilabel Reader (PerkinElmer) and GraphPad Prism 9 (GraphPad Software) were used to measure the testosterone levels. The mean testosterone concentration of the negative control group was subtracted as a background from the testosterone concentration of each sample group. Subsequently, the relative $\%$ of the mean testosterone level in the mLBP group relative to the mean testosterone level (control $=100 \%)$ in the control group was calculated, and the results are presented as the mean $\pm \mathrm{SD}(\mathrm{n}=4$ each).

Cell viability was measured using the Cell counting kit (Catalog no. CK04, Dojindo, Tokyo, Japan) according to the manufacturer's instructions WST-8 reagent was added to the culture supernatants of cells of the control group, abiraterone treatment group, and the mLBP treatment group ( 10 or $300 \mu \mathrm{g}$ per mL Flag-tagged $\mathrm{mLBP}$ ) at $10 \mu \mathrm{L}$ per well. After $2 \mathrm{~h}$ of culturing at $37^{\circ} \mathrm{C}$ in a $\mathrm{CO}_{2}$ incubator, the absorbance of $450 \mathrm{~nm}$ was measured by an Envision Multilabel Reader (PerkinElmer; $n=4$ each). Ratios ( $\%$ of control) of the various groups were compared with the mean measurement value of the control group, which served as a reference.

\section{$\underline{\text { Statistical Analysis }}$}

Data are presented as mean $\pm \mathrm{SD}$. An investigation between 2 groups (t-test or Welch's t test) or multiple groups (Dunnett's test) was performed, and the significance probability was set at $\mathrm{p}<0.05$. 


\section{Ethical statement}

All animal experiments were approved by the Animal Experiment Committee of the International University of Health and Welfare (Approval Number: 18022NA) and followed the ARRIVE guidelines (Animal Research: Reporting of In Vivo Experiments) as well as the National Institutes of Health Sciences guidelines. Efforts were made to minimize animal suffering and to reduce the number of animals used.

\section{Data availability}

The datasets generated and analyzed in this study are available from the corresponding author upon request.

\section{References}

1. Broekmans, FJ. et al. Ovarian aging: mechanisms and clinical consequences. Endocr Rev. 30, 465-493 (2009)

2. Ferraretti, AP. et al. ESHRE consensus on the definition of 'poor response' to ovarian stimulation for in vitro fertilization: the Bologna criteria. Hum Reprod. 26, 1616-1624 (2011) 3. Jacobsk, SL. et al. Effect of age on response to human menopausal gonadotropin stimulation. J Clin Endocrinol Metab. 71, 1525-1530 (1990).

4. Balasch, J. et al. Is luteinizing hormone needed for optimal ovulation induction?. Curr Opin Obstet Gynecol. 14, 265-274 (2002).

5. Sharara, FI. et al. The detection of diminished ovarian reserve in infertile women. Am J Obstet Gynecol. 179, 804-812 (1998).

6. Zhai, J. et al. In Vitro Activation of Follicles and Fresh Tissue Auto-transplantation in Primary Ovarian Insufficiency Patients. J Clin Endocrinol Metab. 101, 4405-4412 (2016).

7. Osuga, Y. et al. Derivation of functional antagonists using N-terminal extracellular domain of gonadotropin and thyrotropin receptors. Mol Endocrinol. 11, 1659-1668 (1997)

8. Klett, D. et al. Low reversibility of intracellular cAMP accumulation in mouse Leydig tumor cells (MLTC-1) stimulated by human Luteinizing Hormone (hLH) and Chorionic Gonadotropin (hCG). Mol Cell Endocrinol. 434, 144-153 (2016)

9. Zhuandi, G. et al. FSH receptor binding inhibitor restrains follicular development and possibly attenuates carcinogenesis of ovarian cancer through down-regulating expression levels of FSHR and ER $\beta$ in normal ovarian tissues. Gene. 668, 174-181 (2018)

10. Ji, Y. et al. Epitope-specific monoclonal antibodies to FSH $\beta$ increase bone mass. Proc Natl Acad Sic U S A. 115, 2192-2197 (2018). 
11. Wortmann L, et al. Discovery of BAY-298 and BAY-899: Tetrahydro-1,6naphthyridine-Based, Potent, and Selective Antagonists of the Luteinizing Hormone Receptor Which Reduce Sex Hormone Levels in Vivo. J Med Chem. 62, 10321-10341 (2019)

12. Jia, XC. et al. Granulosa cell aromatase bioassay for follicle-stimulating hormone: validation and application of the method. Endocrinology. 119, 1570-1577 (1986)

13. Geisse $\mathrm{S}$, et al. Large-scale transient transfection of mammalian cells: a newly emerging attractive option for recombinant protein production. J Struct Funct Genomics. 6, 165 170 (2005)

14. Dufau ML, et al. In vitro bioassay of LH in human serum: the rat interstitial cell testosterone (RICT) assay. J Clin Endocrinol Metab. 42, 958-969 (1976)

15. Caprio M, et al. Expression of functional leptin receptors in rodent Leydig cells. Endocrinology. 140, 4939-4947 (1999)

16. Puett, D. et al. A functional transmembrane complex: the luteinizing hormone receptor with bound ligand and G protein. Mol Cell Endocrinol. 260-262, 126-136 (2007)

17. Grewal, N. et al. Computer modelling of the interaction between human choriogonadotropin and its receptor. Protein Eng. 7, 205-211 (1994)

18. Orisaka M, et al. Dysregulation of ovarian follicular development in female rat: LH decreases FSH sensitivity during preantral-early antral transition. Endocrinology. 154, 2870$2880(2013)$

\section{Acknowledgement}

We thank Aaron J.W. Hsueh (Stanford University School of Medicine, Stanford, CA, USA) for critical reading and editing of the manuscript. This work was supported by The Japan Society for the Promotion of Science (JSPS), Scientific Research B (19H03801), Challenging Exploratory Reseaech (18K19624) (to K.K.), and Japan Agency for Medical Research and Development (to K.K.), and research funding from Tsumura Co.Ltd (to K.K.).

\section{Author contribution}

Y.Y., Y.S. and K.K all contributed to the design of work, the interpretation of results and the writing and review of manuscript. Y.Y. conducted all experiments, data analyses and prepared figures. Y.S. oversaw data collection, KK conducted project management.

\section{Additional information}

Competing interests

The authors declare no competing interests. 


\section{FIGURE LEGENDS}

Fig. 1 Genetic construction and production of mouse LH-binding protein (mLBP).

A) Plasmid map of mouse LtCD8 fusion gene.

The pcDNA 3.1(+)-mouse LtCD8 fused gene was constructed by replacing the human LHCGR of pcDNA 3.1(+)-human LtCD8 with the extracellular domain sequence (1-1077 bp) of the PCR-amplified mouse LHCGR. PRL SP: prolactin signal peptide, $6 \mathrm{H}: 6 \times$ His.

\section{B) Expression of LtCD8 and LBP in transfected Expi293F cells.}

Left: human LBP and mLBP liberated in a cell-culture supernatant after the thrombin cleavage reaction. Right: human LtCD8 and mouse LtCD8 in cell lysate after the thrombin cleavage reaction. Expi293F cells were transfected with pcDNA 3.1(+)-mouse LtCD8 gene, and after 3 days, thrombin cleavage was performed to harvest free mLBP in the culture supernatant detected by immunoblot using anti-FLAG antibody. The groupings of blots cropped from two parts of the same gel were displayed.

\section{Fig. 2. Binding affinity of mLBP against mouse LH and FSH.}

\section{A) Free LH and FSH concentrations in the mLBP-OVX mouse serum mixture.}

In the control group, $12.5 \%$ sera collected from ovariectomized (OVX) mice and vehicleenriched supernatant were mixed while in the mLBP group, 12.5\% OVX-mouse sera and mLBP-enriched culture supernatant ( $300 \mu \mathrm{g} / \mathrm{mL}$ Flag-tagged mLBP) were mixed. Each mixture was added to the anti-FLAG M2 affinity gel to trap the complex of mLBP and gonadotropins on the affinity gel, and the concentrations of unbound free gonadotropins in the filtrate were measured using the Milliplex Mouse Pituitary kit. Mean $\pm \mathrm{SD}$ ( $\mathrm{n}=3$ each). ${ }^{*} \mathrm{P}<0.05$ vs. control.

\section{B) Detection of mLBP eluted from the anti-FLAG M2 agarose affinity gel.}

The mLBP bound to anti-FLAG M2 agarose affinity gel was eluted by competition using $3 \mathrm{x}$ FLAG peptide, and detected by immunoblot with the anti-FLAG antibody.

\section{Fig. 3. Bioactivity test of mLBP using sera from ovariectomized mice in MLTC-1 cells.}

\section{A) Sera from ovariectomized mice induce cAMP production.}

MLTC-1 cells were treated with sera from sham-operated or ovariectomized mice (sham-mouse or OVX-mouse sera) for $1 \mathrm{~h}$, and intracellular cAMP concentrations were measured using the homogeneous time-recovered fluorescence $\left(\mathrm{HTRF}^{\circledR}\right)$ assay kit. Mean $\pm \mathrm{SD}(\mathrm{n}=4$ each). $* \mathrm{P}<$ 0.05 vs. control.

\section{B) Inhibitory effect of mLBP on cAMP production induced by OVX-mouse serum.}

The cells were treated with 5\% OVX-mouse sera and mLBP-enriched culture supernatants (indicated by Flag-tagged mLBP) for $1 \mathrm{~h}$, and intracellular cAMP levels were measured. The 
relative $\%$ of the cAMP levels in the mLBP group to the level in the control group (control = $100 \%$ ) was calculated. Mean $\pm \mathrm{SD}(\mathrm{n}=4$ each). $* \mathrm{P}<0.05$ vs. control.

\section{C) Inhibitory effect of mLBP on testosterone production induced by OVX-mouse serum.}

The cells were treated with 5\% OVX-mouse sera and mLBP-enriched culture supernatants (indicated by Flag-tagged mLBP) or $100 \mathrm{nmol} / \mathrm{L}$ abiraterone (CYP17 inhibitor; CYP17-I). After $24 \mathrm{~h}$, testosterone levels in the supernatants were measured using the $\mathrm{HTRF}^{\circledR}$ assay kit. The relative $\%$ of the testosterone level in the mLBP or CYP17-I group to the control group (control $=100 \%)$ was calculated. Mean $\pm \mathrm{SD}(\mathrm{n}=4$ each). $* \mathrm{P}<0.05$ vs. control.

\section{D) Cell viability.}

The cells were treated with 5\% OVX-mouse sera and $100 \mathrm{nmol} / \mathrm{L}$ CYP17-I or mLBP-enriched culture supernatants ( 10 or $300 \mu \mathrm{g} / \mathrm{mL}$ Flag-tagged mLBP) for $24 \mathrm{~h}$. The viability was measured using a cell counting kit. The relative \% of absorbance in the CYP17-I or mLBP group to the control (control $=100 \%)$ was calculated. Mean $\pm \mathrm{SD}(\mathrm{n}=4$ each). $* \mathrm{P}<0.05$ vs. control.

\section{Fig.4 Effect of mLBP on FSH activity in 293 cells stably expressing mouse FSH receptors.} The 293 cells stably expressing mouse FSH receptors were treated with sera from shamoperated or ovariectomized mice (sham-mouse or OVX-mouse sera) for $1 \mathrm{~h}$.

\section{A) OVX-mouse sera induce cAMP production.}

Intracellular cAMP levels were measured using a homogeneous time-resolved fluorescence $\left(\mathrm{HTRF}^{\circledR}\right)$ assay kit. Mean $\pm \mathrm{SD}(\mathrm{n}=4$ each). $* \mathrm{P}<0.05$ vs. control.

\section{B) Inhibitory effect of mLBP on cAMP production induced by OVX-mouse serum.}

The cells were treated with 5\% OVX-mouse sera and mLBP-enriched culture supernatants (indicated by Flag-tagged mLBP) for $1 \mathrm{~h}$, and intracellular cAMP levels were measured. The relative $\%$ of the cAMP levels in the mLBP group to the level in the control group (control= $100 \%$ ) was calculated. Mean $\pm \mathrm{SD}(\mathrm{n}=4$ each). $* \mathrm{P}<0.05$ vs. control.

\section{Fig.5 Inhibitory effect of mLBP on rhLH activity in MLTC-1 cells.}

\section{A) Binding affinity of mLBP against human LH (hLH).}

In the control group, $1 \mathrm{ng} / \mathrm{mL}$ recombinant human $\mathrm{LH}(\mathrm{rhLH})$ and vehicle-enriched supernatant were mixed while in the $\mathrm{mLBP}$ group, $1 \mathrm{ng} / \mathrm{mL}$ rhLH and $\mathrm{mLBP}$-enriched culture supernatant $(100 \mu \mathrm{g} / \mathrm{mL}$ Flag-tagged mLBP) were mixed. Each mixture was added to the anti-FLAG M2 affinity gel to trap the complex of $\mathrm{hLH}$ and $\mathrm{mLBP}$ on the affinity gel, and the concentrations of unbound free $\mathrm{hLH}$ in the filtrate were measured using hLH ELISA kit. Mean $\pm \mathrm{SD}$ ( $\mathrm{n}=3$ each). $* \mathrm{P}<0.05$ vs. control.

\section{B) Detection of mLBP eluted from the anti-FLAG M2 agarose affinity gel.}

The mLBP bound to anti-FLAG M2 agarose affinity gel was eluted by competition using $3 \mathrm{x}$ 
FLAG peptide, and detected by immunoblot with the anti-FLAG antibody.

\section{C) rhLH induces cAMP production.}

MLTC-1 cells were treated with $1 \mathrm{ng} / \mathrm{mL}$ rhLH for $1 \mathrm{~h}$. Intracellular cAMP levels were measured using a homogeneous time-resolved fluorescence $\left(\mathrm{HTRF}^{\circledR}\right)$ assay kit. Mean $\pm \mathrm{SD}$ ( $\mathrm{n}=4$ each). ${ }^{*} \mathrm{P}<0.05$ vs. control. ${ }^{*} \mathrm{P}<0.05$ vs. control.

\section{D) Inhibitory effect of mLBP on rhLH-induced cAMP production.}

MLTC-1 cells were treated with $1 \mathrm{ng} / \mathrm{mL}$ rhLH and mLBP-enriched culture supernatants (indicated by Flag-tagged mLBP) for $1 \mathrm{~h}$, and intracellular cAMP levels were measured. The relative $\%$ of the cAMP levels in the mLBP group to the level in the each control group (control $=100 \%)$ was calculated. Mean $\pm \mathrm{SD}(\mathrm{n}=4$ each). $* \mathrm{P}<0.05$ vs. control. 


\begin{tabular}{|c|c|c|c|c|c|}
\hline $\begin{array}{c}\text { PRL } \\
\text { SP }\end{array}$ & FLAG & $6 \mathrm{H}$ & $\begin{array}{c}\text { Mouse LH receptor } \\
\text { Extracellular domain } \\
(1-1077 \mathrm{bp})\end{array}$ & $\begin{array}{c}\text { Thrombin receptor } \\
\text { Cleavage site }\end{array}$ & $\begin{array}{c}\text { CD8 } \\
\text { Transmembrane } \\
\text { site }\end{array}$ \\
\hline
\end{tabular}

Chimeric protein induction on plasma membrane

\begin{tabular}{|c|c|c|c|c|}
\hline FLAG & $6 \mathrm{H}$ & $\begin{array}{c}\text { Mouse LH receptor } \\
\text { Extracellular domain } \\
(1-359 \mathrm{aa})\end{array}$ & $\begin{array}{c}\text { Thrombin receptor } \\
\text { Cleavage site } \\
(36-66 \mathrm{aa})\end{array}$ & $\begin{array}{c}\text { CD8 } \\
(183-235 \mathrm{aa})\end{array}$ \\
\hline
\end{tabular}

Thrombin cleavage reaction

\begin{tabular}{|c|c|c|}
\hline FLAG & $6 \mathrm{H}$ & $\begin{array}{c}\text { Mouse LH receptor } \\
\text { Extracellular domain }\end{array}$ \\
\hline
\end{tabular}

Mouse LH-binding protein (mLBP)

Fig. 1 Genetic construction and production of mouse LH-binding protein (mLBP). 


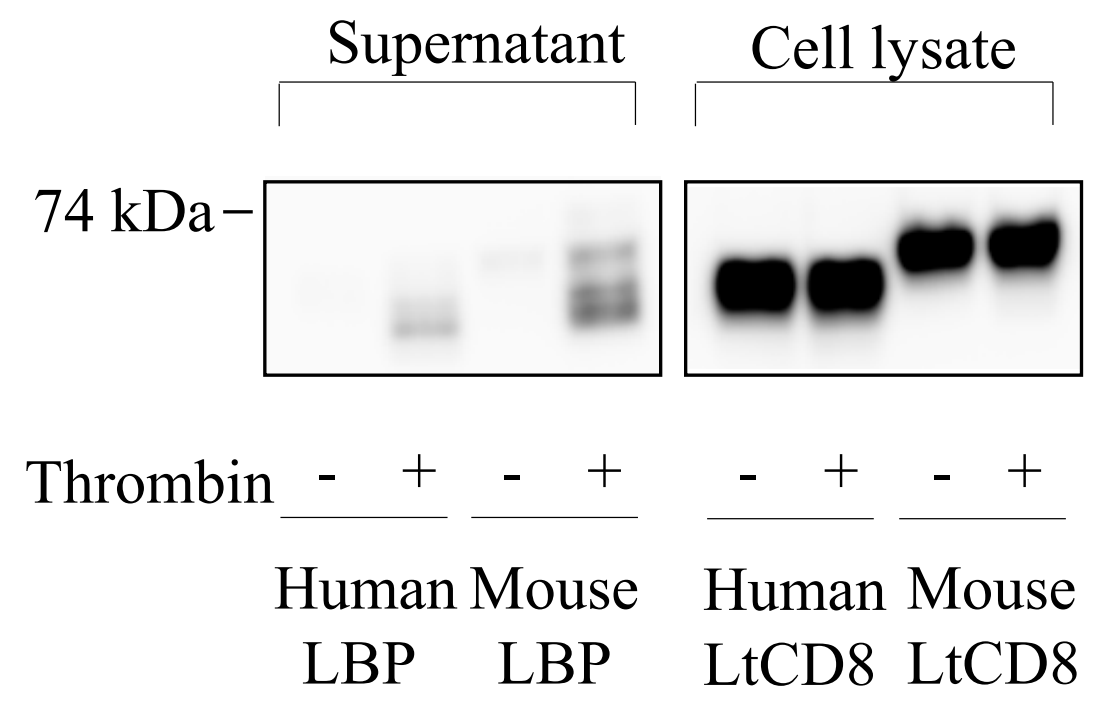

Fig. 1 Genetic construction and production of mouse LH-binding protein (mLBP). 

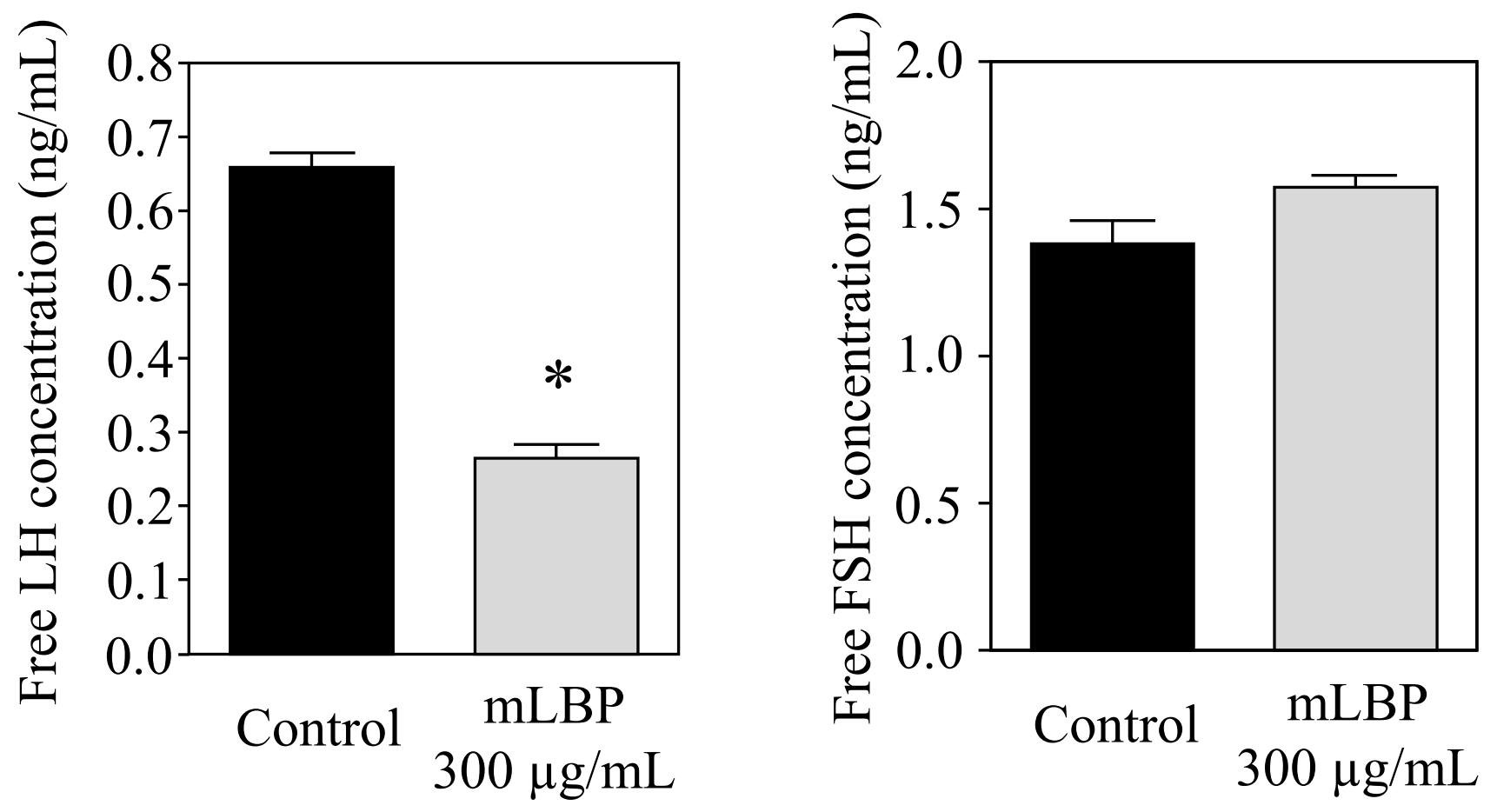

Fig. 2 Binding affinity of mLBP against mouse LH and FSH. 


\section{B)}

$$
\begin{aligned}
& 80 \mathrm{kDa}- \\
& 60 \mathrm{kDa}- \\
& 50 \mathrm{kDa}-
\end{aligned}
$$

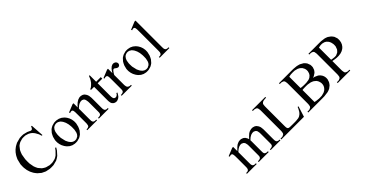

Fig. 2 Binding affinity of mLBP against mouse LH and FSH. 


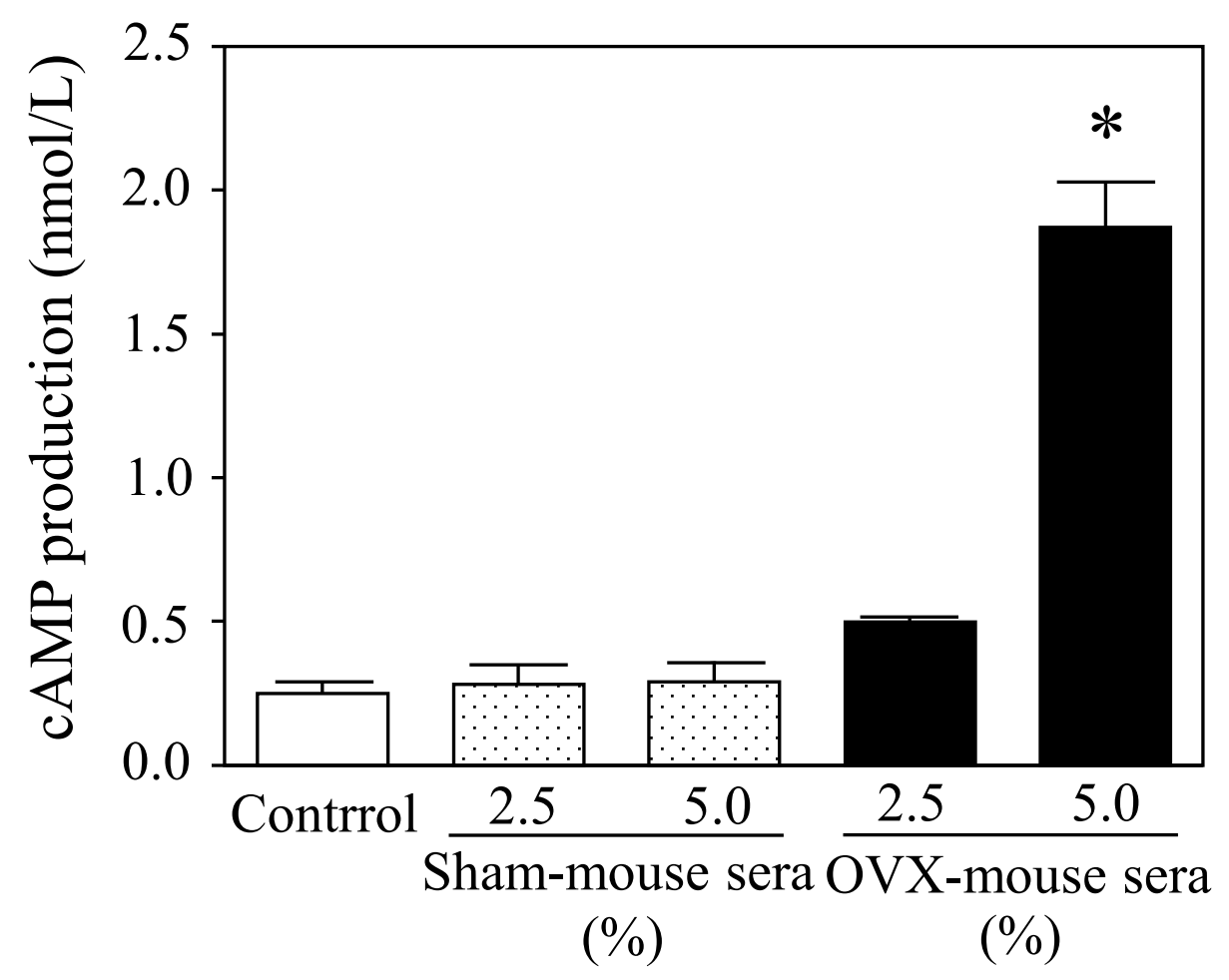

Fig. 3 Bioactivity test of mLBP using sera from ovariectomized mice in MLTC-1 cells. 


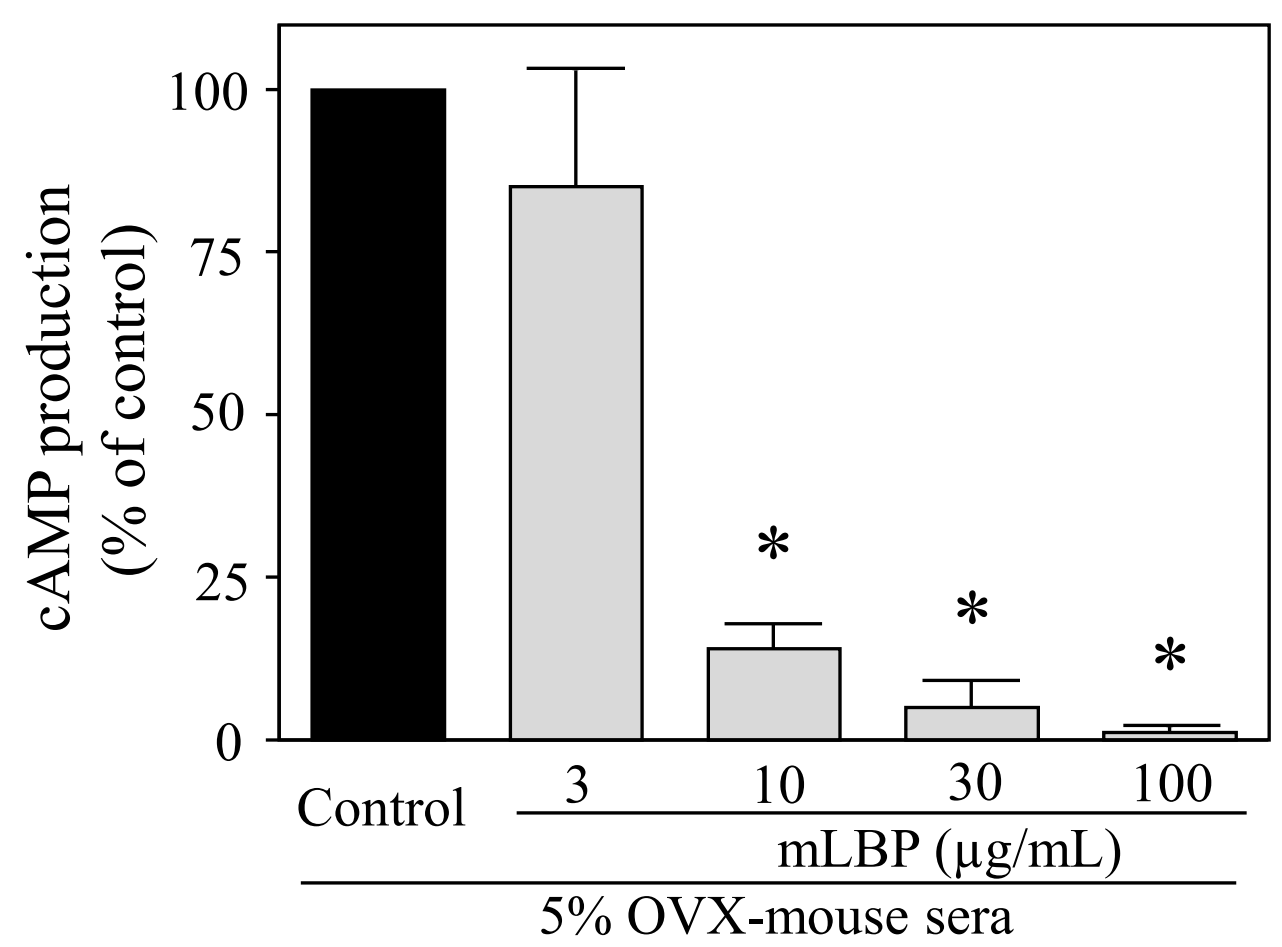

Fig. 3 Bioactivity test of mLBP using sera from ovariectomized mice in MLTC-1 cells. 


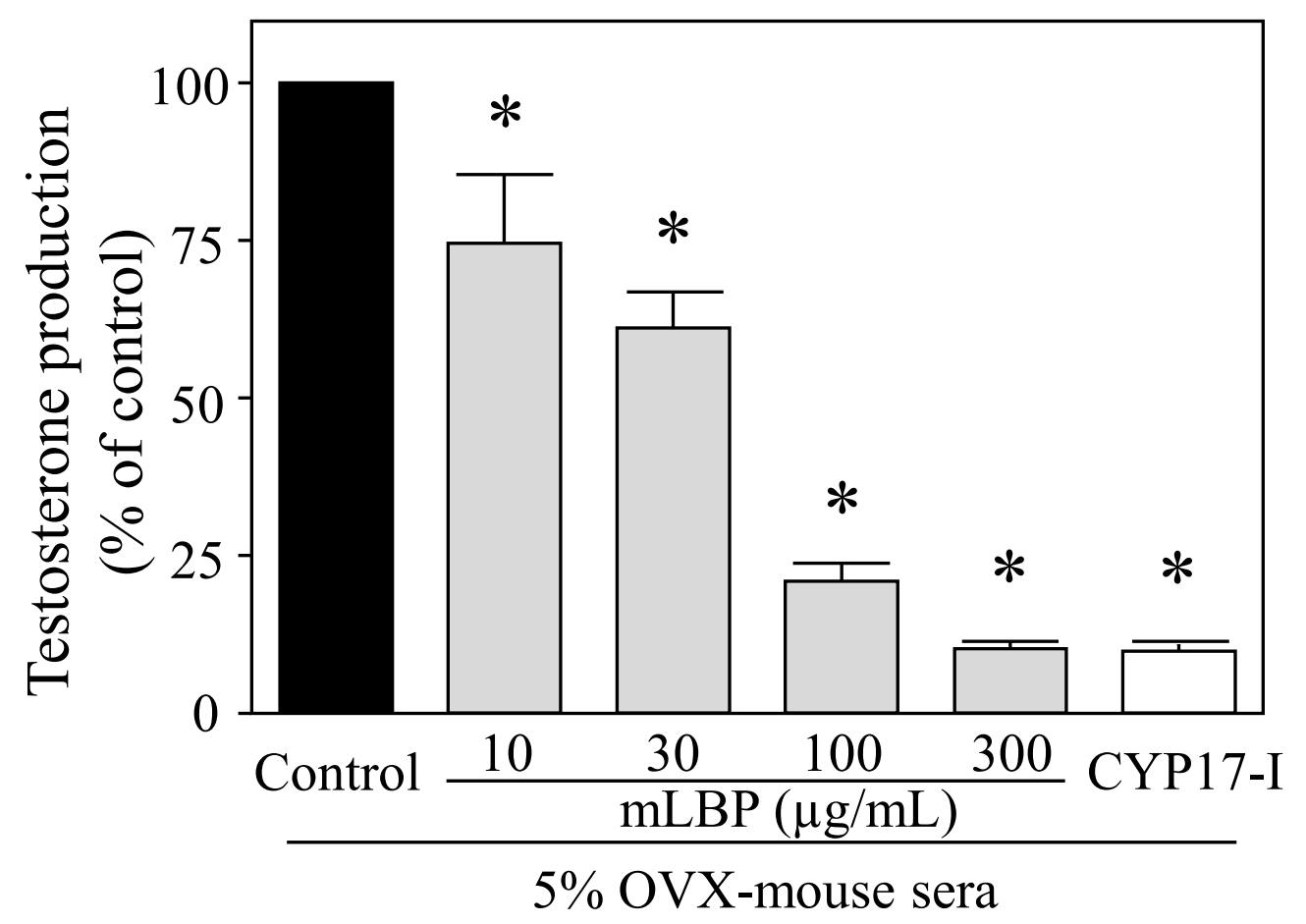

Fig. 3 Bioactivity test of mLBP using sera from ovariectomized mice in MLTC-1 cells. 


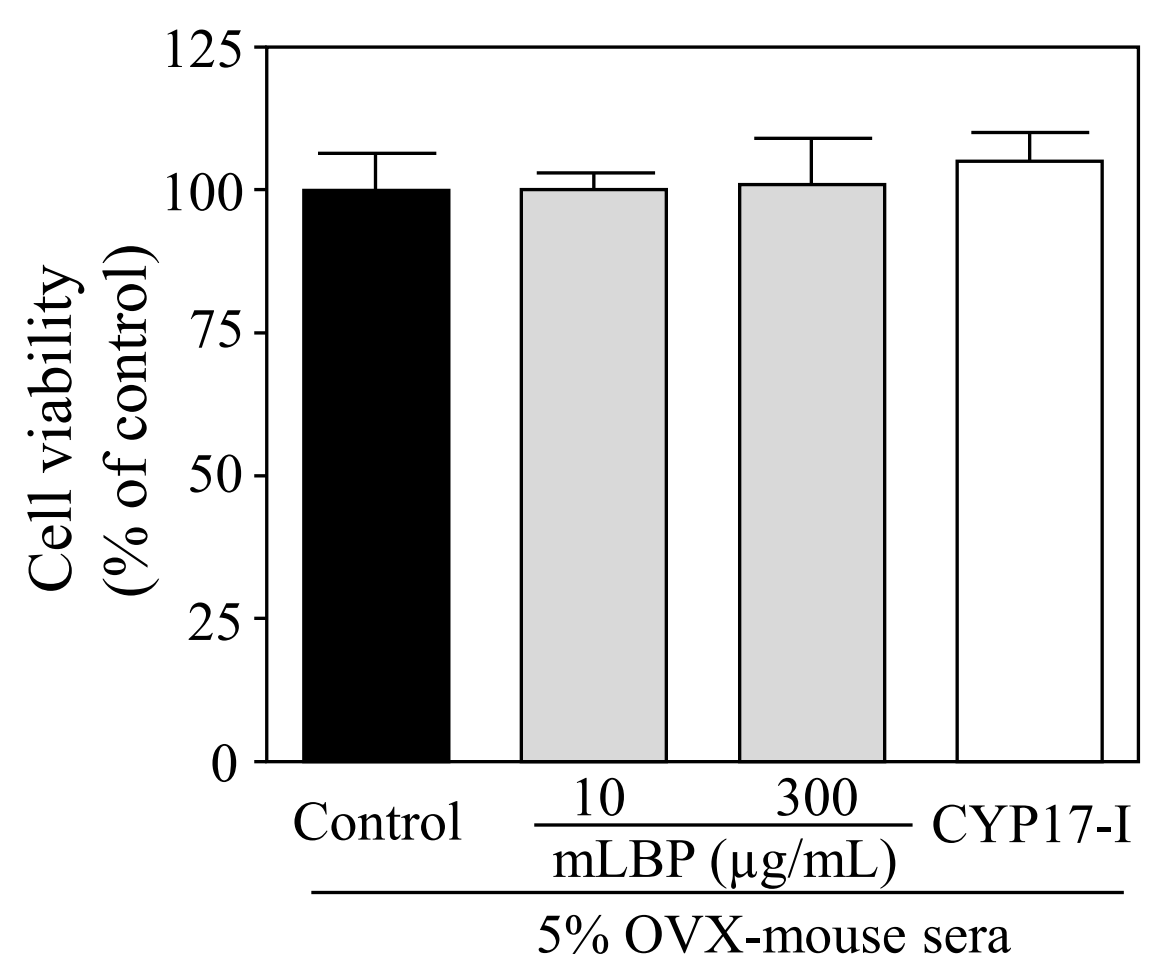

Fig. 3 Bioactivity test of mLBP using sera from ovariectomized mice in MLTC-1 cells. 


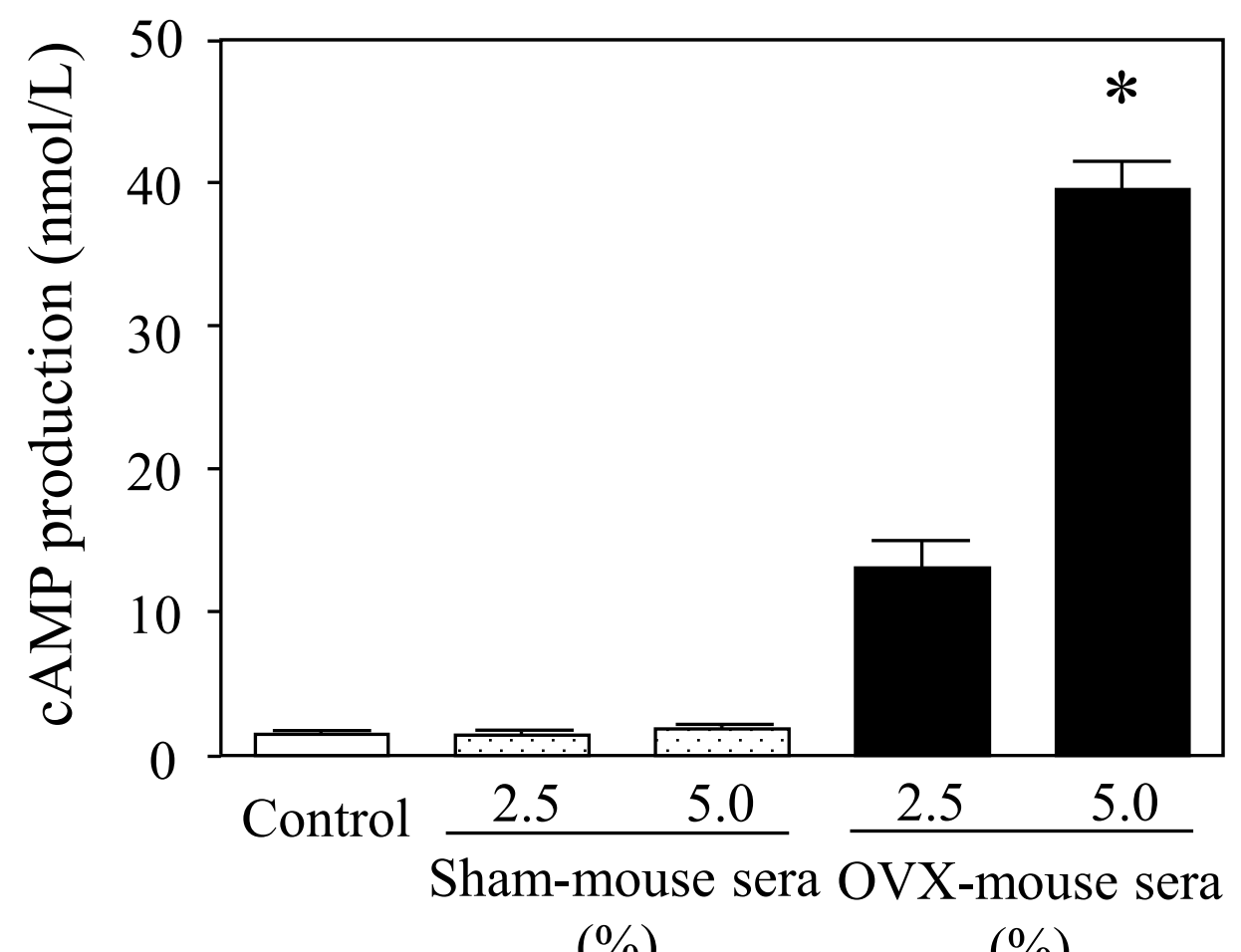

(\%)

(\%)

Fig. 4 Effect of mLBP on FSH activity in 293 cells stably expressing mouse FSH receptors. 


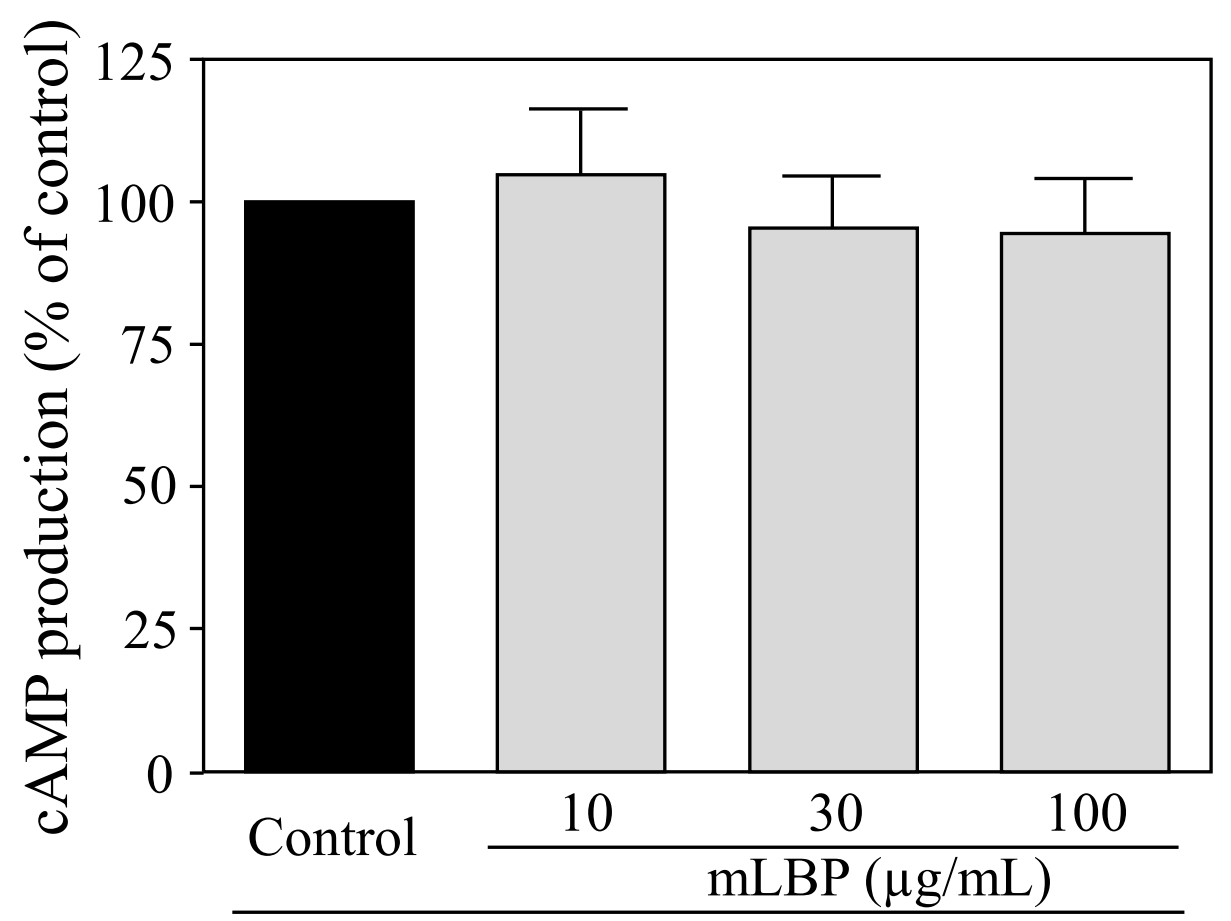

5\% OVX-mouse sera

Fig. 4 Effect of mLBP on FSH activity in 293 cells stably expressing mouse FSH receptors. 


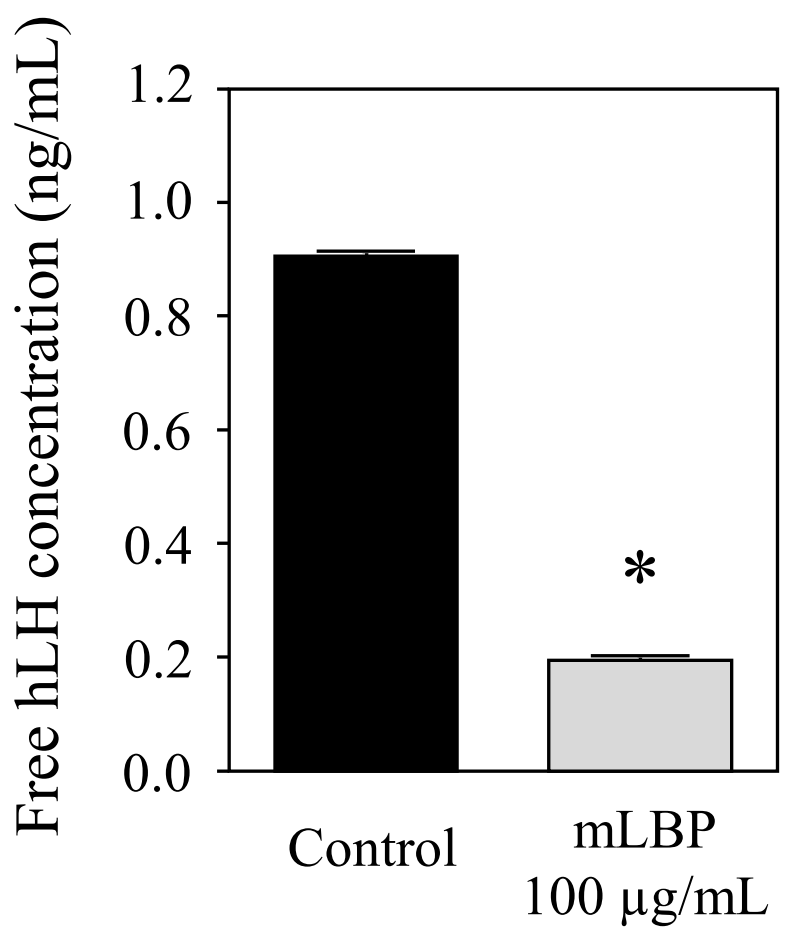

Fig. 5 Inhibitory effect of mLBP on human LH activity. 

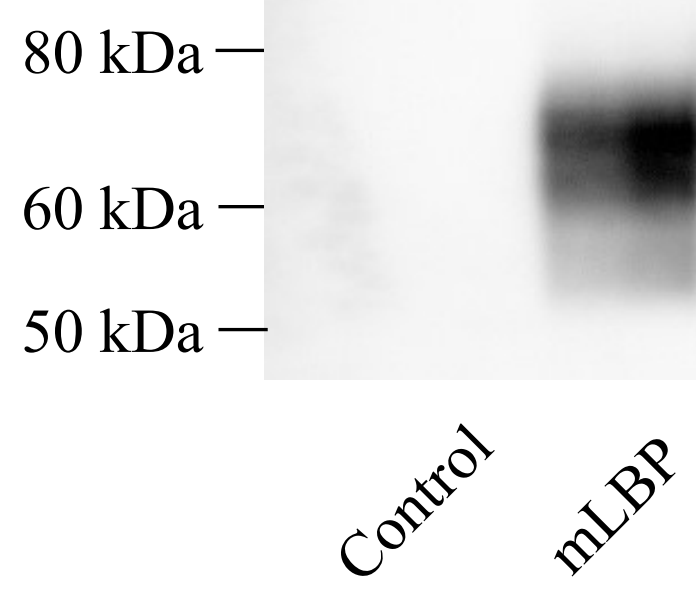

Fig. 5 Inhibitory effect of mLBP on human LH activity.

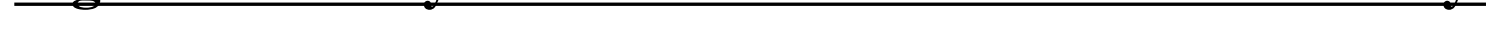




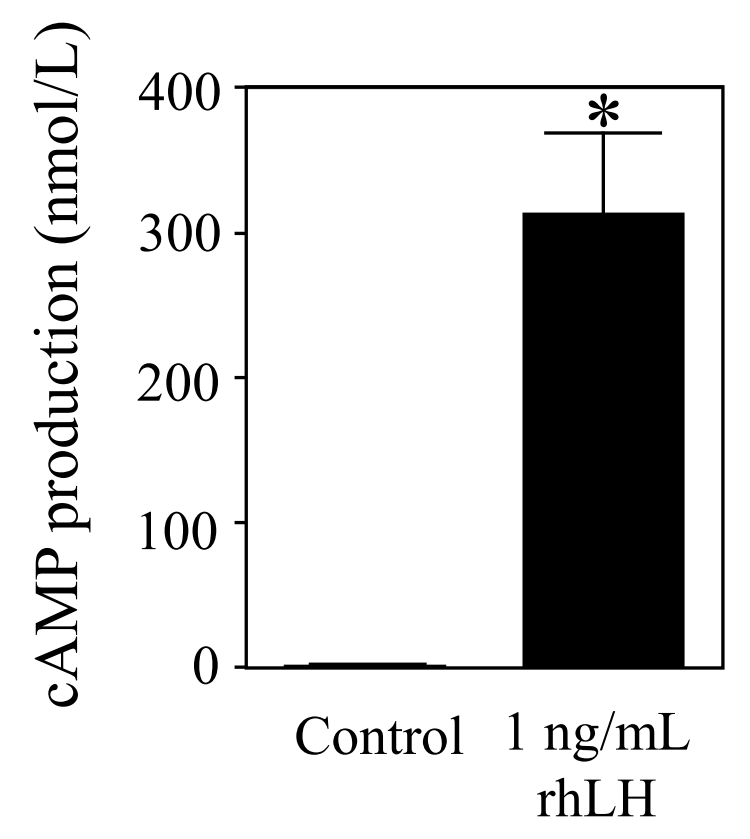

Fig. 5 Inhibitory effect of mLBP on human LH activity. 


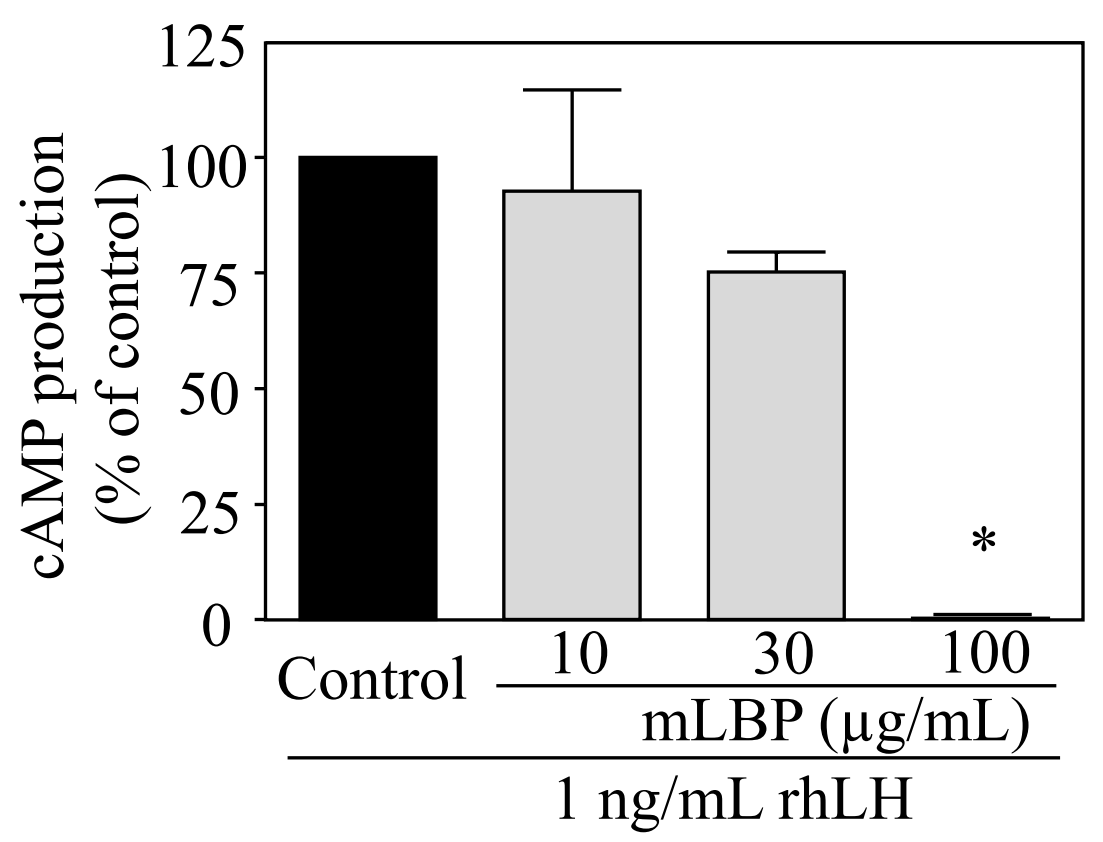

Fig. 5 Inhibitory effect of mLBP on human LH activity. 


\section{Supplementary Files}

This is a list of supplementary files associated with this preprint. Click to download.

- SupplementaryinformationmouseLBPYamaguuchietal.pdf 